Proceedings

\title{
Managing Uncertainty in the Face of Certain Dangers
}

\author{
Joy L. Hart 1,2,*, Lindsey A. Wood ${ }^{1,2}$ and Kandi L. Walker ${ }^{1,2}$
}

1 Department of Communication, 310 Strickler Hall, University of Louisville, Louisville, Kentucky, USA 40292; joy.hart@louisville.edu, lindsey.wood.1@louisville.edu, kandi.walker@louisville.edu

2 Christina Lee Brown Envirome Institute, School of Medicine, University of Louisville, 302 E. Muhammad Ali Boulevard, Louisville, Kentucky, USA 40202; joy.har@@louisville.edu, lindsey.wood.1@louisville.edu, kandi.walker@louisville.edu

* Correspondence: Correspondence: joy.hart@louisville.edu; Tel.: +01-502-852-6976

\begin{abstract}
We examine the effects of the COVID-19 pandemic on a community-based research project. This clinical trial investigates whether increased neighborhood greenness lowers the risk of cardiovascular disease through reduction of air pollution. Facilitating the project involves considerable community engagement, and the project relies on successful collaboration across a multidisciplinary team. As concerns surrounding SARS-CoV-2 increased, adjustments to our research were needed. When cases of COVID-19 escalated, clinical trials were halted. In this analysis, we employ a dialectical approach to examine the competing tensions evidenced in community work during the pandemic. From the vantage point of dialectical theory, competing feelings can occur simultaneously (such as concurrent experiences of dissatisfaction-satisfaction or need for progress-need for safety) and influence experience. This analysis considers dialectical tensions created by the pandemic as well as the means of reconciling some tensions and wrestling with others.
\end{abstract}

Keywords: community health; greenness; dialectics; community engagement; partnerships; COVID-19 pandemic; SARS-CoV-2; dialectical tensions

\section{Introduction}

In this work, we examine the effects of the COVID-19 pandemic on a communitybased research project. This clinical trial investigates whether increased neighborhood greenness lowers the risk of cardiovascular disease through reduction of air pollution. Facilitating the project involves considerable community engagement (e.g., an active community advisory board, participation in neighborhood association meetings, collaborations with schools and other organizations, presentations, health education sessions, to name but a few activities), and the project relies on successful collaboration across a large,

Publisher's Note: MDPI stays neutral with regard to jurisdictional claims in published maps and institutional affiliations.

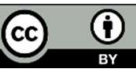

Copyright: (c) 2021 by the authors. Submitted for possible open access publication under the terms and conditions of the Creative Commons Attribution (CC BY) license (http://creativecommons.org/licenses/by/4.0/). multidisciplinary research team. As concerns surrounding SARS-CoV-2 increased, adjustments to our research timeline and activities were needed. When cases of COVID-19 escalated, many U.S. clinical trials were halted, and the pandemic has had numerous effects on ongoing health research [1-5]. While some facets of our project have resumed, most areas involving community work have not returned to face-to-face interaction. These unexpected events have influenced our work in numerous ways, including having to negotiate our own conflicted feelings and those of our team as we simultaneously strive to maintain community partnerships and continue facets of the project that can be completed remotely and/or virtually.

Across the months of halted progress and altered interaction, our research team has simultaneously experienced both frustration and relief. In this analysis, we employ a dialectical approach to examine the competing tensions evidenced in community research work during the pandemic. From the vantage point of dialectical theory, competing feelings can occur simultaneously and influence our views and actions. In particular, we examine concurrent experiences of dissatisfaction-satisfaction, need for progress-need for safety, desires to engage-needs to separate, and wishes to share updates-uncertainty on 
future specifics. This analysis considers the months our community engagement efforts have been affected by the COVID-19 pandemic (March 2020-December 2020), the associated dialectical tensions, and the means of reconciling some tensions and wrestling with others.

Understanding the effects of the pandemic on our team and on our community partners and partnerships is important both in managing the project currently as well as in returning to in-person work once that is possible. Through careful analyses of these impacts, we will be better prepared to resume community work. Because interactants have an array of desires and goals, coexisting influences shape viewpoints in multiple ways [6]. In other words, people sometimes experience concurrent oppositional feelings, such as liking predictability and longing for novelty. At times, one preference may be stronger than the other, but overall people want both, instead of one or the other. Relational dialectics theory examines the ways in which these simultaneously occurring dialectical tensions influence interactions and relationships [7-9]. Such dialectical tensions influence a diverse array of interactions and relationships, such as those in the workplace, with our friends, with romantic partners, and in families. Often examined dialectical tensions center in competing wants for predictability-novelty, integration-separation, and opennessclosedness [10] and are evidenced through communication [11]. Via communication, we signal to others our expectations and wants, though this messaging is not always clear and, from the perspective of relational dialectics theory, can be imbued with opposing viewpoints [11].

Such dialectical tensions are normal and commonplace in our relationships and, although they may cause individual discomfort or relational conflict, are not inherently negative [11]. Given that such tensions regularly occur in our lives and relationships, it is not surprising that they would be frequent in times of rapid change and uncertainty, such as during a public health crisis. The COVID-19 pandemic is one such crisis that both perpetuated and highlighted oppositional views. For example, while needing to remain physically distant, there were many urges to seek social support by gathering together. In this analysis, we discuss dialectical tensions experienced by our research team regarding community engagement initiatives. Below we discuss these tensions, how they have influenced our team and work, and how we are addressing and seeking to resolve these competing wants.

\section{Pandemic Dialectal Tensions}

As touched on above, one set of opposing tensions that we dealt with was the need to separate-desire to engage. Although public health recommendations (as well as our university and funding partners) called for a halt to in-person gatherings, we still wanted to engage with our community members and work together. Thus, we had to balance our want to connect with the greater demands for preserving public health and become comfortable with some level of discomfort in this area.

In a related vein, we addressed a competing tension of the need for progress-need for safety. Deep commitment to the community and the project propelled us to want to continue achieving goals; however, we simultaneously recognized that pausing many facets of the work was needed to try to ensure the safety of community partners and our team members. We addressed this tension by continuing our previous types of virtual engagement as well as devising additional ones. For example, beyond regular newsletters and social media posts, we began hosting periodic virtual Community Conversations about areas of the research and shared more information via infographics.

We also grappled with wishes to share updates-uncertainty on future specifics. The multiyear project had a specific timeline for its various components and this information had been widely shared. Once clinical trials were halted, the original timeline was no longer possible to achieve. When we received inquiries from community members, we wanted to provide accurate updates but simultaneously were not sure when the full project could be recommenced. Additionally, rather than waiting for questions, we wanted 
to share information regarding when facets of the project would begin again; however, we hesitated to provide details until information was clear because we wanted to avoid needing to alter them again if possible.

An additional dialectic was a combined feeling of dissatisfaction-satisfaction. Across the months, feelings of dissatisfaction and satisfaction have been inextricably linked for our team. We are dissatisfied to have so much on hold, to be unclear when we can return to the fieldwork, and to be unable to share detailed information; at the same time, we are satisfied with how we have dealt with the issues to date, the methods of pursuing new ways of maintaining connection with the community, and the overall response from and engagement of community partners.

\section{Reconciling and Wrestling}

Since the COVID-19 pandemic altered our research plans, relationships within our team and with community partners have experienced challenges. Although disruptive in many ways, these challenges also have presented opportunities for reflection and growth. In some cases, we have been able to temporarily reconcile tensions by acknowledging them and discussing them openly; in others, we have devised strategies to overcome negative effects. For example, we have incorporated additional virtual meetings and events to our ongoing work, which preserves some of the community dialogue and engagement. These shifts have encouraged more creativity and more dialogue, which have helped relationships to grow. The shifts also have foregrounded the importance of human connection, reinforcing people's desires to connect with others and to build relationships. At times, we still wrestle with how best to navigate some of the dialectical tensions. For example, although we can share some information about future plans, we do not know when returning to all parts of the work will possible; thus, we are still grappling with certaintyuncertainty dimensions and must repeatedly address this tension.

\section{Conclusions}

Addressing the COVID-19 pandemic has presented many challenges and required an array of adjustments. The pandemic's effects on clinical trials will reverberate for years to come. Community-based research endeavors, which rely on relationships with community members and organizations, encountered even greater hurdles. Some of the hurdles can be surmounted with creativity and effective communication. Others require ongoing attention and continued adaptations to effectively address. Once we are able to fully resume face-to-face work in the community, we hope that the benefits of wrestling with these dialectical tensions will be evident in stronger team relationships and increased understanding as well as deepened trust and partnership with the community.

Author Contributions: All authors participated in conceptualizing, analyzing, and writing (editing and reviewing). JLH prepared the original written draft. All authors have read and agreed to the published version of the manuscript.

Funding: This work was supported, in part, by grants from the National Institute of Environmental Health Sciences of the National Institutes of Health (NIH; Award Numbers R01 ES 029846 and P42 ES023716), The Nature Conservancy (TNC), and the Christina Lee Brown Envirome Institute at the University of Louisville. The content is solely the responsibility of the authors and does not necessarily represent the official views of the NIH, TNC, or the University of Louisville.

Acknowledgments: We wish to thank our many community partners for their continued support of this research project and their participation in virtual meetings and events during the COVID-19 pandemic. We also extend thanks to other members of our research team and the project's many multidisciplinary collaborators. Additionally, we acknowledge support from the Department of Communication at the University of Louisville. 
Conflicts of Interest: The authors declare no conflict of interest. The funders had no role in the design of the study; in the collection, analyses, or interpretation of data; in the writing of the manuscript; or in the decision to publish the results.

\section{References}

1. Stawicki, S.P.; Jeanmonod, R.; Miller, A.C. et al. The 2019-2020 Novel Coronavirus (Severe Acute Respiratory Syndrome Coronavirus 2) Pandemic: A Joint American College of Academic International Medicine-World Academic Council of Emergency Medicine Multidisciplinary COVID-19 Working Group Consensus Paper. J Glob Infect Dis 2020, 12(2), 47-93. doi:10.4103/jgid.jgid_86_20

2. Mitchell, E.J.; Ahmed, K.; Breeman, S. et al. It is unprecedented: Trial management during the COVID-19 pandemic and beyond. Trials 2020, 21, 784. https://doi.org/10.1186/s13063-020-04711-6

3. Tuttle, K.R. Impact of the COVID-19 pandemic on clinical research. Nat Rev Nephrol 2020, 16, 562-564. https://doi.org/10.1038/s41581-020-00336-9

4. McDermott, M.M.; Newman, A.B. Preserving clinical trial integrity during the coronavirus pandemic. JAMA 2020, 323(21), 2135-2136. doi:10.1001/jama.2020.4689

5. AlNaamani, K.; AlSinani, S.; Barkun, A.N. Medical research during the COVID-19 pandemic. World J Clin Cases 2020, 8(15), 3156-3163. doi:10.12998/wjcc.v8.i15.3156

6. Bakhtin, M.M. The Dialogic Imagination: Four Essays; Holquist, M., Ed.; Emerson, C.; Holquist, M., Trans.; University of Texas Press: Austin, Texas, USA; 1981.

7. Baxter, L.A. A dialectical perspective of communication strategies in relationship development. In Handbook of Personal Relationships; Duck, S., Ed.; Wiley: New York, USA, 1988; pp. 257-273.

8. Montgomery, B. A dialectical analysis of the tensions, functions and strategic challenges of communication in young adult friendships. In Communication Yearbook 12; Anderson, J.A.; Sage: Newbury, California, USA, 1988; pp. 157-189.

9. Baxter, L.A.; Montgomery, B.M. Relating: Dialogues and Dialectics; Guilford: New York, USA; 1996.

10. Brown, B.B.; Werner, C.M.; Altman, I. Choice points for dialecticians: A dialectical-transactional perspective on close relationships. In Dialectical Approaches to Studying Personal Relationships; Montgomery, B., Baxter, L., Eds.; Erlbaum: Mahwah, New Jersey, USA, 1998; pp. 137-154.

11. Baxter, L.A.; Braithwaite, D.O. Relational dialectics theory. In Engaging Theories in Interpersonal Communication: Multiple Perspectives; Baxter, L.A., Braithwaite, D.O., Eds.; Sage: Thousand Oaks, California, USA, 2008; pp. 349-361. 